increases carbonic-anhydrase activity to $68.8 \mathrm{v} / \mathrm{g}$ and at the total dose of $1 \mathrm{mg}$ to $94.7 \mathrm{U} / \mathrm{g}$ (activity of control animals: $13.7 \mathrm{U} / \mathrm{g})$.

At 1-2 $\mathrm{mg} /$ day subcutaneously injected dioxyprogesterone shows a deciduomatogenic activity in ovariectomized rats ${ }^{4}$ of the same order of that of progesterone.

Dioxyprogesterone maintains pregnancy in ovariectomized mice at a subcutaneous dose of $5 \mathrm{mg} /$ day $(97$ per cent foetuses alive at the end of pregnancy) and in ovariectomized rabbits at the oral daily dose of $10 \mathrm{mg}(63.5$ per cent of fortuses alive).

While most progestins virilize foctuses, dioxyprogesterone does not influence the ano-genital distance or causes morphological changes in the secondary sexual characters of female and male rats born from mothers treated from the 15 th to the 20 th day of pregnancy with doses up to $50 \mathrm{mg}$ day subcutaneous or per os. Dioxyprogesterone presents no androgenic or myotrophic properties both by oral or subcutaneous route ${ }^{5}$. It does not increase the weight of the uterus of young immature female mice. Its antiœestrogenic activity ${ }^{6}$ is about 0.89 times that of progesterone and its anti-gonadotrophic effect? is only 0.08 times that of testosterone propionate (subcutaneous administration).

Up to a dose of $5 \mathrm{mg} /$ day both by oral and subcutaneous route, dioxy-progesterone does not alter the cstral cycle in normal female rats.

It does not possess any corticoid effects (survival of adrenalectomized rats, liver glycogen deposition, antiinflammatory properties, sodium-retaining activity).

$$
\begin{aligned}
& \text { G. Arcari } \\
& \text { G. Baldratti } \\
& \text { G. SALA }
\end{aligned}
$$

Laboratori Ricerche Farmitalia,

Milano, Italia.

McPhall, M. K., J. Physiol., 83, 145 (1934).

Gaddum, J. H., Pharmacology, 522 (Oxf. Univ. Press, 1959).

${ }^{3}$ Lutwak-Mann, C., and Adams, C. E., J. Endocrinol., 15, 43 (1947).

- Chambon, Y., C.R. Soc. Biol. 146, 1095 (1952).

Hershberger, I. G., Shipley, E. G., and Meyer, R. K., Proc. Soc. Exp. Biol. and Med., 83, 175 (1953).

'Edgren, R. A., and Calhoun, D. W., Proc. Soc. Exp. Biol. and Med., 94,

Hertz, R., and Meyer, R. K.. Endocrinol., 21, 756 (1937).

${ }^{8}$ Revesz, C., Endocrinol., 66, 144 (1960).

\section{Effect of Posterior Pituitary Polypeptides on the Flow of Urine after Injection in Lateral Ventricle of the Brain of a Cat}

Prfviovs observations in this laboratory have indicated that the injection of catecholamines and certain posterior pituitary polypeptides into the lateral ventricle of tho cat is associated with characteristic and drugspecific pressor-depressor responses of the peripheral circulation ${ }^{1}$. During the course of these earlier experiments, it was noted that the intraventricular introduction of posterior pituitary polypoptides was followed by a prompt increase of flow in urine. Other observers have reported that the peripheral administration of various posterior pituitary preparations may, on occasion, be attended by a rise of urine flow consequent to a solute diuresis ${ }^{2,3}$. The present experiments were designed to define certain aspects of the 'diuretic' effect of these drugs during their central administration.

Using standard renal clearance techniques, acceptable experiments were obtained in 30 healthy cats maintained on normal diet of cat chow. Appropriate local anæsthetic techniques were used in place of general anæsthesia. After curarization of the animal, respiration was maintained with a positive-pressure respirator through a tracheotomy tube. After surgical exposure of the urethra, an indwelling Foley catheter was placed in the bladder under direct vision in order to secure complete bladder emptying. A constant infusion of creatinine via the femoral vein was maintained after the initial dose. When creatinine equilibration occurred, control clearance periods of 5-20 min were obtained. Control rates of flow of urine were differed by changing the rate of infusion of creatinine. When the flow of urine was stabilized at at constant rate, the drugs were injected into the left lateral ventricle via a 21 tapered needle inserted under stereotaxic control. Sandoz $L 8$ vasopressin (10-15 units), Sandoz $P L V 2$ vasopressin $(0 \cdot 5-1 \cdot 0$ unit), surgical pituitrin $(1 \cdot 0-3 \cdot 5$ units $)$, oxytocin $(0 \cdot 5-1 \cdot 5$ units $)$, and hypertensin Ciba $(0.005 \mathrm{mg})$ were used and after drug injection additional clearanco periods were obtained.

Blood samples were drawn at the mid-point of every third clearance period for the determination of creatinine, osmolality, sodium, potassium and chloride. Similar measurements were performed on each urine sample. Blood pressure and pulse were recorded at appropriate intervals throughout the study. Respirations were constant at the rate of $24 / \mathrm{min}$. Calculations of creatinine cloarance, osmolar clearance, and either freo-water clearance or $T_{c} \mathrm{H}_{2} \mathrm{O}$ were made for all clearanco periods.

The $L 8$ vasopressin was associated with a significant rise of urine flow and no change was noted with $P L V 2$, surgical pituitrin, oxytocin and hypertensin. It appears that this effect is most evident after administration of the $L 8$ vasopressin at low rates of urine flow. In most studies, the increased urine flow was accompanied by an increased osmolar clearanco which could be attributed to an increased excretion of sodium. Since filtration-rate and plasma sodium usually remained unchanged or decreased slightly, the observed solute diuresis may be tentatively attributed to a diminished tubular re-absorption of sodium. This effect could not be prevented by prior trans-section of the spinal cord at the $C-1$ lovol. Peripheral administration of the samo amounts of $L 8$ vasopressin under similar conditions of study was followod by the usual antidiuretic response unassociatod with changes of electrolyte excrotion.

Additional studies are still in progress to evaluate the exact nature of this $L 8$ vasopressin 'diuretic' effect more conclusively. Tentatively, the present findings suggest that the central administration of this drug produces renal effects which are dissimilar to those obtained after the peripheral administration of identical amounts of drug. Although the stimulus may be mediated via the nervous system, furthor studies are needed to evaluato the relative roles of neural and humoral factors to ite occurrence.

B. S. Nashold, Jun.

E. M. Mannarino

R. R. ROBINSON

Department of Neurosurgery,

Department of Medicine,

Duke University and V. A. Hospital, Durham,

North Carolina.

'Nashold, B. S., Mannarino, E., and Wunderlich, M., Nature 193, 1297 (1962).

Shannon, J. A., J. Exp. Med., 76, 387 (1942).

${ }^{3}$ Smith, H. W., The Kidney. Structure and Function in Health and Disense (Oxford Univ. Press, 1951).

\section{Relation between Calcium lons and the Action of Serotonin on a Fundus Strip of the Rat}

According to Gaddum ${ }^{1}$ and Vano $^{2}$ serotonin added to the medium in which smooth muscle is suspended causes muscular contraction. The mechanism of tho action. however, is not understood. In the mechanical response of isolated muscle, changes in the membrane permeability and ionic movements are supposed to be involved. Some observations support the view that ionic movements across the cell membrane establish a binding chain between 